\title{
DOG 1 EXPRESSION IN DIFFERENTIAL DIAGNOSIS OF CHONDROBLASTOMAS AND ITS HISTOLOGICAL MIMICKERS
}

\author{
Maryam Nisar, Sajid Mushtaq, Usman Hassan, Noreen Akhtar, Muhammad Azam \\ Shaukat Khanum Memorial Cancer Hospital and Research Centre, Lahore Pakistan
}

\begin{abstract}
Objective: To assess the sensitivity and specificity of DOG 1 in the diagnosis of chondroblastomas.

Study Design: Comparative cross-sectional study.

Place and Duration of Study: Department of Histopathology, Shaukat Khanum Memorial Cancer Hospital and Research Centre, Lahore, Pakistan, from Jun 2015 to Jul 2017.

Methodology: Total fifty-two patients were included in this study using simple random sampling technique including 19 chondroblastomas, 21 giant cell tumors and 12 chondromyxoid fibromas. DOG 1 antibody was applied on all the cases.

Results: DOG 1 was positive in $100 \%$ of cases of chondroblastomas. However, intensity and proportion of staining pattern was variable among them. Fifteen $(78 \%)$ cases showed diffuse moderate to strong expression while $4(22 \%)$ cases showed focal weak expression. Only $2(10 \%)$ cases of giant cell tumors and $4(33 \%)$ cases of chondromyxoid fibromas expressed focal weak expression for DOG 1.

Conclusion: This study confirms 100\% expression of DOG 1 in cases of chondroblastomas but intensity and proportion of staining pattern was variable. Therefore DOG 1 may prove to be a useful immunohistochemical marker for diagnosis of chondroblastomas in the future in difficult cases in correlation with histological and radiological features.
\end{abstract}

Keywords: Chondroblastoma, Chondromyxoid fibroma, DOG 1, Giant cell tumor, Immunohistochemical marker.

This is an Open Access article distributed under the terms of the Creative Commons Attribution License (http://creativecommons.org/licenses/by/4.0), which permits unrestricted use, distribution, and reproduction in any medium, provided the original work is properly cited.

\section{INTRODUCTION}

Chondroblastoma is a rare benign cartilage forming tumor of bone ${ }^{1}$, comprising $<1 \%$ of the bone tumors 2,3 . It is predominant in second decade of life. Most common sites are epiphysis of the long bones ${ }^{4}$, proximal humerus, tibia and distalfemur. Usual clinical presentation of chondroblastoma is pain with localized inflammation, swelling and joint effusion with limited joint mobility $^{3,5}$. Radiological examination reveals well defined asymmetric, eccentric epiphyseal destruction and bony lytic lesion with a rim of cortical bone and intact borders ${ }^{6-9}$. Histologically, chondroblastoma exhibits round to polygonal chondroblast like cells with eosinophilic chondroid matrix. The cells have well-defined cell borders with grooving and indentation of the nuclei ${ }^{10}$. Moreover, stroma reveals calcifications with delicate lace like pattern and enveloping and linking the

Correspondence: Dr Maryam Nisar, Resident Histopathology, SKMCH, Lahore Pakistan

Received: 03 Mar 2019; revised received: 22 May 2019; accepted: 25 Nov 2020 tumor cells. These calcifications are called "chicken-wire calcifications". The tumor also exhibits osteoclast like giant cells ${ }^{11}$.

In most of the cases the diagnosis is straight forward based on typical histological and radiological features. However, in few cases the histological features overlap between chondroblastomas and its histological mimickers such as giant cell tumors, chondromyxoid fibroma and clear cell chondrosarcoma ${ }^{12}$.

Chondromyxoid fibroma mimics chondroblastoma because of the presence of chondroblast like cells but presence of myxoid stroma, metaphyseal location and absence of chicken wire calcification in chondromyxoid fibroma favor its diagnosis ${ }^{13}$.

Giant cell tumor mimics chondroblastoma due to the presence of giant cells in both entities but age group of giant cell tumor along with absence of chondroblasts usually differentiate it from chondroblastomas 13,2 . 
Until now no definite histological or immunohistochemical marker was available to differentiate between chondroblastomas and other histologically similar entities. Recently DOG 1, a diagnostic marker for gastrointestinal smooth muscle tumor has been proposed as a useful marker for the diagnosis and differential diagnosis of chondroblastomas ${ }^{11,14}$.

DOG 1 is a transmembrane protein that is a calcium activated chloride channel. It is considered a diagnostic immunohistochemical marker for gastrointestinal stromal tumor in the recent studies. DOG 1 is not only expressed in interstitial cells of cajal but also it is expressed in acinar cells of salivary gland and pancreas as well as in chondroblastomas, adenoid cystic carcinomas, synovial sarcomas, adenoid cystic carcinomas, acinic cell carcinomas, renal oncocytomas and chromophobe renal cell carcinomas ${ }^{15,16}$. Therefore, we have conducted a retrospective study at our institution to assess utility of DOG 1 in diagnosis of chondroblastomas, giant cell tumour and chondro-myxoid fibroma

\section{METHODOLOGY}

This study design was a comparative crosssectional study. This study was conducted at Shaukat Khanum Cancer Memorial Hospital and Research Centre Lahore. After approval from the institutional review board a total of 52 cases of chondroblastoma, giant cell tumour and chondromyxoid fibroma were retrieved from computerized database from a period of 2015-2017 through simple random sampling technique. Cases were included irrespective of age, gender and site of the tumor. Autolyzed, scanty, poorly preserved samples were excluded from the study. Correlation with the radiological findings was done before making the final diagnosis.

For all cases, Hematoxylin and Eosin stained slides were reviewed under light microscopic examination by a consultant histopathologist. The relevant clinical data was extracted from electronic medical record including age, gender and location of tumor.
Paraffin blocks were selected for immunohistochemistry. All sections were deparaffinized and incubated with primary antibody DOG 1 . Subsequently, all processes were done as per manufacturer guidelines. Primary antibody, (Merck DOG 1 monoclonal-antibody \# MABC 36, clone) was applied on all the 52 cases tissues using BOND III Leica automated immunostainer. Positive control of gastrointestinal stromal tumor tissue was used to check the accuracy of antibody. Results were interpreted by two pathologists including one consultant in each case.

Membranous and cytoplasmic staining was considered as positive staining. The staining results were interpreted using two variables, intensity and proportion of tumor cells with positive staining. Intensity was categorized as weak, moderate and strong staining while proportion was interpreted as focal staining or diffuse staining pattern. Staining in at least $10 \%$ tumor cells was considered as positive expression for DOG 1 while all the cases showing $<10 \%$ expression was considered as negative. Staining between 10-30\% was considered as focal, while staining in greater than $30 \%$ of tumor cells was considered as diffuse staining.

\section{RESULTS}

There were 19 cases of chondroblastoma, 21 cases of giant cell tumor and 12 cases of chondromyxoid fibroma included in the study. The mean

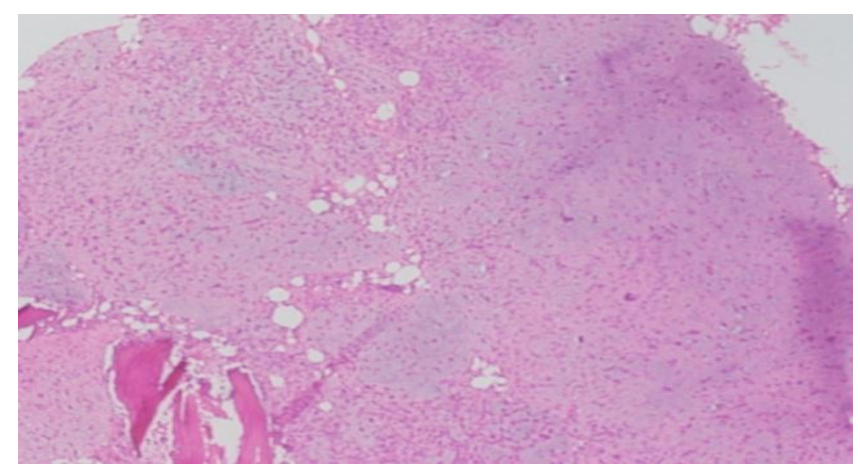

Figure-1: Chondromyxoid fibroma. (H\&E, Magnification $\times 10$ ).

age of the patients was $20 \pm 5$ years. All the 19 $(100 \%)$ cases of chondroblastoma included in the study showed expression for DOG 1 immuno- 
histochemical marker although the intensity and proportion of staining was variable among them, $15(78 \%)$ cases showed moderate to strong intensity and diffuse expression for DOG 1 in the nests of polygonal chondroblasts while $4(22 \%)$ cases exhibited focal and weak expression.

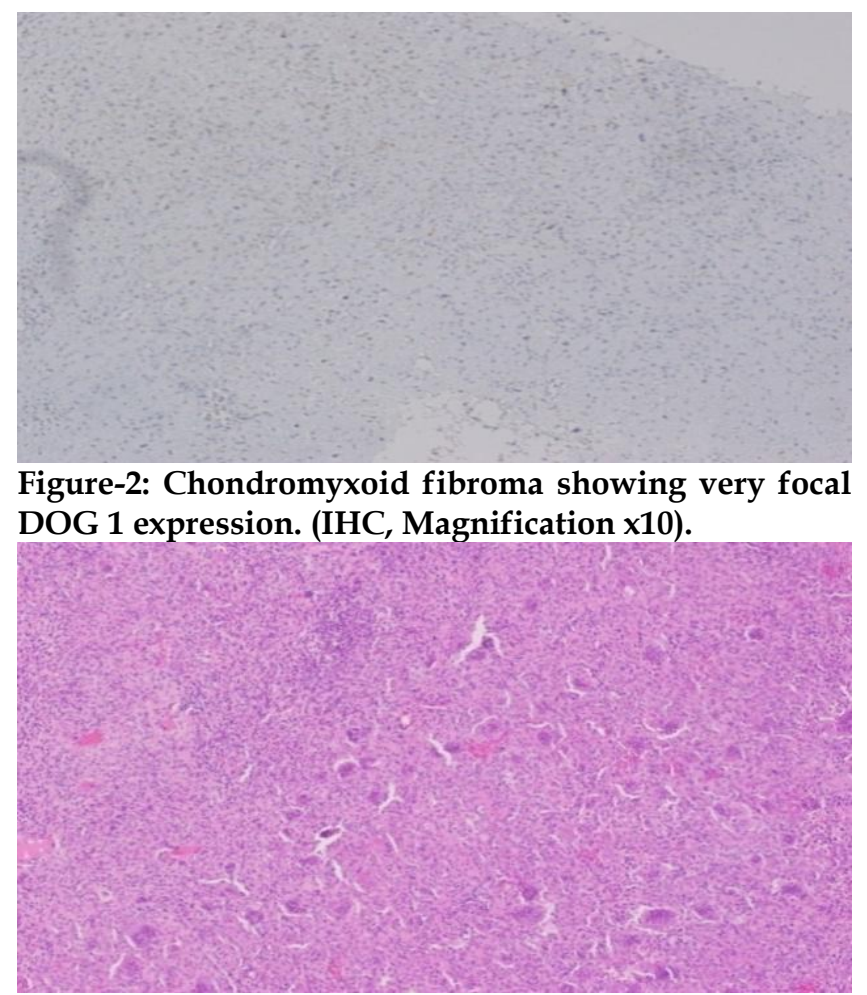

Figure-3: Giant cell tumour. (H\&E, Magnification x10).

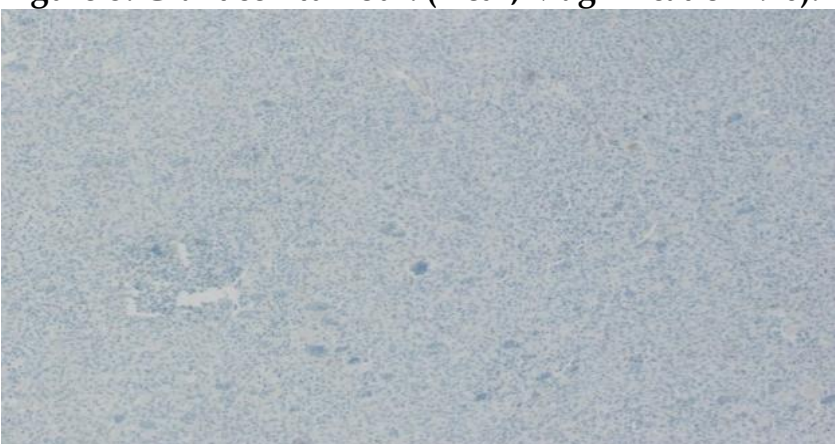

Figure-4: Giant cell tumor with negative DOG 1 expression. (IHC, Magnification x10).

As far as chondromyxoid fibroma is concerned, only $4(33 \%)$ cases out of 12 cases included in the study were positive with very focal and weak intensity of staining for DOG 1 . Remaining $8(66 \%)$ cases of chondromyxoid fibroma were completely negative for DOG 1 with no immunohistochemical expression (fig-1 \& 2).
Out of 21 cases of giant cell tumor included in our study $2(10 \%)$ cases showed focal and weak expression for DOG 1 . The remaining 19 $(90 \%)$ cases were completely negative with no expression in the multinucleated osteoclastic giant cells or the stromal cells (fig-3 \& 4).

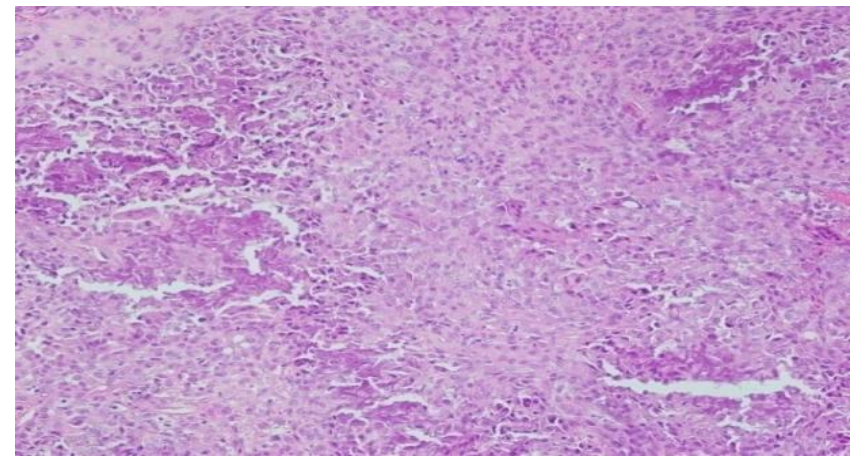

Figure-5: Chondroblastoma (H\&E, Magnification x10).

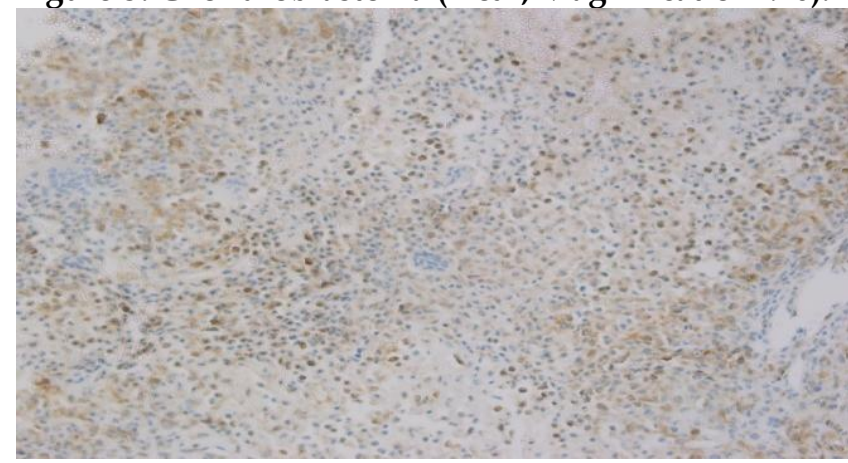

Figure-6: Diffuse DOG 1 expression with moderate to strong intensity in the nests of chondroblasts while multinucleated giant cells are negative. (IHC, Magnification $\times 10$ )

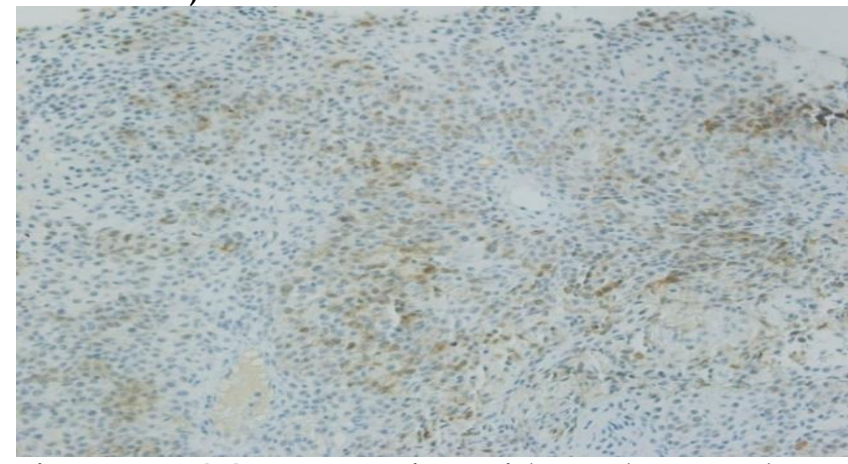

Figure-7: DOG 1 expression with weak to moderate intensity in the nests of chondroblasts while multinucleated giant cells are negative (IHC, Magnification x10).

Histologically chondroblastoma exhibits cellular and fibrous chondroid areas. Cellular areas consist of nests of intermediate sized polygonal 
chondroblasts with eosinophilic cytoplasm, large centrally placed nuclei and longitudinal nuclear grooves giving it a coffee bean appearance. Nucleoli are usually small7. DOG 1 stains the nests of these chondroblasts with membranous and cytoplasmic staining but intensity of staining pattern was weak to moderate with very focal expression in few $(22 \%)$ of the cases. Scattered chondroblasts and multinucleated osteoclast like giant cells are also present $(10 \%)$ which are negative for DOG 1 (fig-5 \& 6).

\section{DISCUSSION}

Chondroblastoma is a rare malignancy of bone $^{5}$. It accounts for less than $1 \%$ of primary bone tumors and predominantly presents in individuals less than 20 year of age. It affects males more frequently as compared to females ${ }^{12}$. It was described by Ewing in 1928 as "calcifying giant cell tumor". Consequently, further terms originated which include epiphyseal chondromatous giant cell tumor and benign chondroblastoma of bone ${ }^{12,17}$. Chondroblastoma is most commonly seen in epiphyseal region. Histological appearance reveals proliferation of nests of chondroblast like cells with grooved coffee bean nuclei along with chic-ken wire calcifications ${ }^{18}$, osteoclast like giant cells and sometimes aneurysmal bone CYST like areas (fig-5) ${ }^{19}$. A definitive diagnosis is essential for appropriate management due to high recurrence rate of this disease $\mathrm{e}^{18,20,21}$.

Many cases have characteristic histological and radiological features making possible a definitive diagnosis however in few cases the histological features overlap with chondromyxoid fibroma, clear cell chondrosarcoma, giant cell tumors and aneurysmal bone cyst ${ }^{22}$. In those cases, application of immunohistochemistry may be helpful for establishing a diagnosis. Few studies have been done in the recent past to analyze the diagnostic utility of different immunohistochemical stains in the diagnosis of chondroblastomas including DOG 111,21.

Total fifty-two cases were included in the study including 19 cases of chondroblastomas, 21 cases of giant cell tumors and 12 cases of chon- dromyxoid fibroma. All the diagnosis was made after radiological correlation.

DOG 1 expression was seen in all 19 (100\%) cases of chondroblastomas. The intensity of staining was moderate to strong in $15(78 \%)$ of the cases while the rest of the $4(22 \%)$ cases showed focal weak expression in the nests of chondroblasts (fig-5 \& 7). Our results are consistent with previously published finding on this subject.

In a study by Arjen et al21 variable results for DOG 1 expression were found depending upon the amount of biopsy material provided by the surgeon, 33\% expression for this marker was seen in core and needle biopsies while weak to moderate expression was present in $100 \%$ of the cases when large biopsy samples were provided by the clinicians. Only 35\% of cases of chondromyxoid fibroma were positive with very weak focal expression and all the giant cell tumors were negative for DOG 1 in respective study. Similar results were obtained in our study with $100 \%$ expression of DOG 1 in chondroblastomas and 33\% in cases of chondromyxoid fibroma. In contrast to the above-mentioned study $10 \%$ of the giant cell tumors showed focal weak expression for DOG 1 but none of the case showed strong diffuse expression in our study ${ }^{21}$.

Another study by Rehkamper et al23, applied DOG 1 on cases of chondroblastoma, giant cell tumors and aneurysmal bone cyst. DOG 1 was positive in 11 out of 14 (78\%) cases of chondroblastomas while it was completely negative in 23 cases of giant cell tumors and 19 cases of aneurysmal bone cyst.

Several other immunohistochemical markers have been used in previous studies to assist in diagnosis of chondroblastomas. Akpalo et al11, studied expression of multiple immunohistochemical markers including DOG 1 on 9 cases of chondroblastomas, 10 cases of chondromyxoid fibroma and 7 cases of giant cell tumors. DOG 1 was positive in $100 \%$ of cases of chondroblastomas with strong membranous expression while chondromyxoid fibroma and giant cell tumors were negative. 
A similar study done by Ali et al20, studied expression for DOG 1 and multiple other immunohistochemical markers in chondroblastoma, giant cell tumors and aneurysmal bone CYST. The study showed positive results for DOG 1 in all the 3 cases of chondroblastomas.

\section{ACKNOWLEDGEMENTS}

The authors would like to thanks Mr Usman Ayub and Mr Ishaq for technical assistance.

\section{CONCLUSION}

To conclude, DOG 1 appears to be a useful diagnostic marker for diagnosis of chondroblastoma. The large specimens show positivity in majority of the cases which may be focal or weak. However smaller biopsy samples can be negative for DOG 1 and clinical, radiological, and histological features remains the gold standard for the diagnosis of this entity with DOG 1 providing a supportive role in difficult cases ${ }^{23}$.

\section{Authorship Contributions}

Dr. Maryam Nisar: acquisition of data, drafting of the article, data analysis, interpretation of data and concept \& design.

Dr. Sajid Mushtaq: Concept and design.

Dr. Usman Hassan: Data analysis and interpretation of results.

Dr. Noreen Akhtar: Review of the article.

Dr. Muhammad Azam: Review of the article

\section{CONFLICT OF INTEREST}

The authors of this study have no conflict of interest to declare.

\section{REFERENCES}

1. Santini-Araujo E, Kalil RK, Bertoni F, Park YK. Tumors and tumor-like lesions of bone: for surgical pathologists, orthopedic surgeons and radiologists: Springer 2015. https://www. springer.com/gp/book/9781447172437.

2. Amary MF, Berisha F, Mozela R, Gibbons R, Guttridge A, O'donnell $\mathrm{P}$, et al. The H3F3 K36M mutant antibody is a sensitive and specific marker for the diagnosis of chondroblastoma. Pathol 2016; 69(1): 121-27.

3. Favril A, Brys P, Pilate I, Vanhoenacker F. Chondroblastoma of the proximal tibia. Eurorad 2017. https://www.eurorad. org/ case/14513.

4. Lambert J, Verstraeten T, Mermuys K. Chondroblastoma: An Unusual Cause Of Shoulder Pain In Adolescence. J Belgian Society Radiol 2016; 100(1): 1-16.

5. Angelini A, Hassani M, Mavrogenis AF, Trovarelli G, Romagnoli C, Berizzi A, et al. Chondroblastoma in adult age. Eur J Orthop Surg Traumatol 2017; 27(6): 843-49.

6. Tiwari M, Chaturvedi H, Patel V. Chondroblastoma of the medial malleolus: a case report of a rare tumor at an extremely uncommon site. J Orthop Case Reports 2016; 6(1): 29-32.

7. Davila JA, Amrami KK, Sundaram M, Adkins MC, Unni KK. Chondroblastoma of the hands and feet. Skeletal Radiol 2004; 33(10): 582-7.

8. Venkatasamy A, Chenard M, Massard G, Steib JP, Bierry G. Chondroblastoma of the thoracic spine: a rare location. Case report with radiologic-pathologic correlation. Skeletal Radiol 2017; 46(3): 367-72.

9. Sharma M, Khan SW, Velho V, Mally R. Intra-axial chondroblastoma: A bony tumor in the cerebral hemisphere-a case report and review of literature. Asian J Neuro 2017; 12(2): 266-3.

10. Konishi E, Nakashima Y, Mano M, Tomita Y, Kubo T, Araki N, et al. Chondroblastoma of extra craniofacial bones: clinicopathological analyses of 103 cases. Pathol Int 2017; 67(10): 495-02.

11. Akpalo H, Lange C, Zustin J. Discovered on gastrointestinal stromal tumour 1 (DOG1): a useful immunohistochemical marker for diagnosing chondroblastoma. Pathol 2012; 60(7): 1099-06.

12. De Mattos CB, Angsanuntsukh C, Arkader A, Dormans JP. Chondroblastoma and chondromyxoid fibroma. Am Acad Orthop Surg 2013; 21(4): 225-33.

13. Srevatsa K, Kangle RP, Kangle P, Haveri S. Chondromyxoid fibroma at an unusual site. J Scientific Society 2018; 45(2): 106-09.

14. Kiśluk J, Zińczuk J, Kemona A, Guzińska-Ustymowicz K, Żurawska J, Kędra B. Expression of CD117, DOG-1, and IGF-1R in gastrointestinal stromal tumours-an analysis of 70 cases from 2004 to 2010. Prz Gastroenterol 2016; 11(2): 115-22.

15. Hirota S. Differential diagnosis of gastrointestinal stromal tumor by histopathology and immunohistochemistry. Transl Gastroenterol Hepatol 2018; 3(1): 27-38.

16. Talmon G, Odum B, Swanson B, DiMaio D. DOG-1 Is Not an Immunohistochemical Marker of Acinar Cell Carcinoma of the Pancreas. Am J Clinical Pathology 2015; 144(suppl-2): A361.

17. Chen W, DiFrancesco LM. Chondroblastoma: an update. Arch Pathol Lab Med 2017; 141(6): 867-71.

18. Ozkoc G, Gonlusen G, Ozalay M, Kayaselcuk F, Pourbagher A, Tandogan RN. Giant chondroblastoma of the scapula with pulmonary metastases. Skelet Radiol 2006; 35(1): 42-48.

19. Özer D, Arıkan Y, Gür V. Chondroblastoma: An evaluation of the recurrences and functional outcomes following treatment. Acta Orthopaedica Traumatol Turcica 2018; 52(6): 415-18.

20. Ali L, Pop D. Differential diagnosis of benign tumors of bone rich in giant cells, based on immunohistochemistry. Romanian J Orthopaedic Surgery Traumatol 2018; 1(Supplement): 49-55.

21. Cleven AH, Briairede Bruijn I, Szuhai K. DOG 1 exp-ression in giant cell containing bone tumours. Pathol 2016; 68(6): 942-45.

22. Kiefer RM, Wojcik J, Cooper K, Weber KL, Sebro R. Clear Cell Chondrosarcoma With Chondroblastoma-Like Features: A Case for Team Diagnosis. Inter J Surg Pathol 2018; 26(8): 766-71.

23. Rehkämper J, Steinestel K, Jeiler B, Elges S, Hekeler E, Huss S, et al. Diagnostic tools in the differential diagnosis of giant cell-rich lesions of bone at biopsy. Oncotarget 2018; 9(53): 30106. 